\title{
XXVII. On electricity
}

\section{Ez. Walker Esq.}

To cite this article: Ez. Walker Esq. (1813) XXVII. On electricity , Philosophical Magazine Series 1, 42:185, 161-163, DOI: $10.1080 / 14786441308638307$

To link to this article: http://dx.doi.org/10.1080/14786441308638307

$$
\text { 曲 Published online: } 27 \text { Jul } 2009 .
$$

Submit your article to this journal 전

LII Article views: 3

Q View related articles $\asymp$ 


\section{$\left[\begin{array}{lll}161 & \end{array}\right]$ \\ XXVII. On Electricity. By Ez. WaLKgR, Esq. \\ To Mr. Tilloch.}

Sin, A Frea all the hypotheses that have been invented to explain the phenomena of electricity, philosophers still cntertain various opinions respecting the electric fluid. Some maintan that the spark is produced by two fluids passing through each other in contrary directions, forming a dnuble current; but others are of opinion, that it consists of only one divided into two parts, which they call positive and negative electricity; whilst others even hesitate 10 admic the existence of the electric fluid, as completely established.

As many of the phrnomena of nature are produced by electrical energy, and as no conclusion dirawn from doubtful principles can be admitted in philosophy, it secms indispensably neccsony, that this disputed point should be determined by clear and satisfactory experiments.

When a card is perforated by an electric spark, it is well known that a bur is raised on each side. This experiment has often been advanced as a proof that two positive powers pass through the card in contrary directions; but this conclusion is too hypothetical to be admitted as a physical truth, and every other experiment that has yet been made to investigate this point, is equally uncertain.

As many of the effects of electricity are strictly mechanical ; the following experiments demonstrate, on that principle, that the electric spark consists of two forces passing through each other in contrary directions.

Experiment 1. Let a piece of tin-foil, about two inches long and an inch broarl, be laid berween two cards, with their ends fixed together wish gum-water or varnish; and let $A B C D$ (fig. 2. Plate 1I.) represent those cards when laid on a table, $e p$ a piece of wire laid upon the cards, and $n h$ another piece of wire laid under them; the distance $h e$ between the conds of the wires being ahout an inch.

A charge from a large Leyden jar being passed through the wires, a perforation was made in the top card at $\epsilon$, with an indent downwards, in the tin-foil and bottom card, under that point. The under card was also perforated at the end of the wire $h$, and at timat point the tin-foil and upper card were indented upwards.

This experiment was repeated many times, without any variation in the phenomend, except that one end of the tin-foil was sometimes periorated.

Now it is evident from this experiment, that the power Vol.42. No. 185. Sept. 1813. L L from 


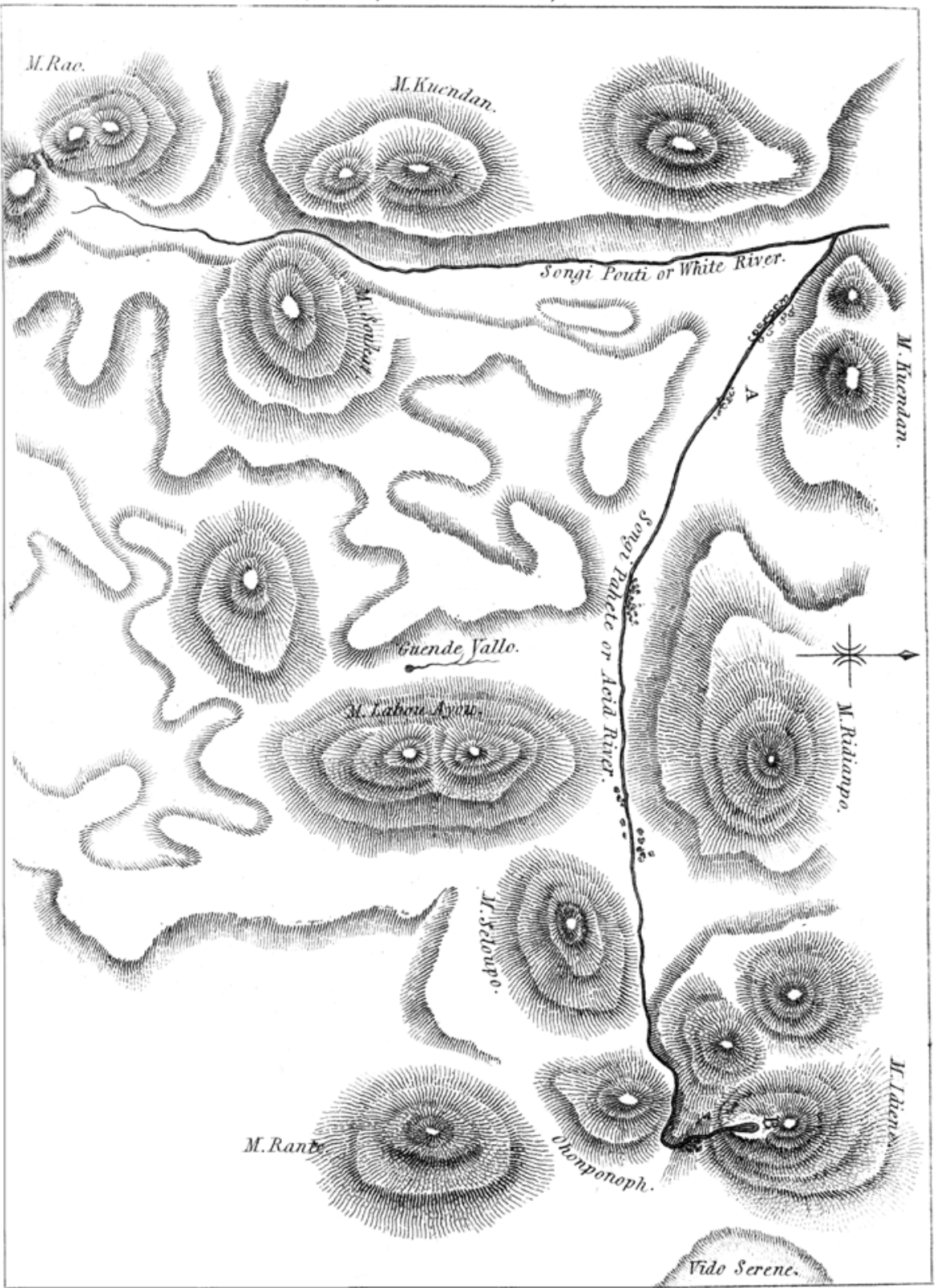

S. Potter, sculp. 
from the inside of the jar passed from $p$ to $n$, because an indent was made downwards at the point $e$; and it is aloo evident, that the power from the outside of the jar passed in the direction from $n$ to $p$, as an indent was made $u p$ wards at the point $h$. Hence we may fairly conclude, that the electric spark consists not of one power only, but of two distinct positive powers acting in contrary directions and towards each other.

Experiment 2. I placed a single card upon a table, with a piece of wire tpon it and another piece under it, so that their ends were one above the other; then two other cards were taken, and a piece of tin-foil placed upon the centre of each. One of these cards was placed under the bottom wire, with the tin-foil tuwards, and the other was placed upon the top wire, the tin-foil being downwards.

An electric charge being passed through the two wires produced the same phtnomena as those before mentioned; the middle card was perforated, the tin-foil upon the under card was indented downuards, but that upon the upper was indented upwards.

I communicated these experiments to Mr. Murray, philosophical lecturer, requesting him to repeat them, and the following is extracted from his answer, dated Swaffham, 17 th July, 1813 :

" 1 took a single card," says Mr. Murray, " and placed one wire above it and another below, with the ends one above the other," \&ce. and proceeded as you direct: the result proved your conclusion to be correct, for the tinfoil both above and below the perforation was indented and in contrary directions.

"The theory of two powers moving contrariwise receives validity from the following experiment. The cards and tin-foil slips being used as before, I placed two points below instead of one, with one above; two corresponding indents were made on the tin-foil upwards and only one downwards. I reversed the experiment, and the two points being above the card, there appeared two indents donunwards and only one upuards.

"I repeated these with uniform phrnomena and unvarying results.

"r You will think, I doubt not, with me, that the last mode of conducting the experiment places the subject in a point of view, beyond a doubt of the conclusion we have mutually drawn.

$$
\text { "I am, dear sir, with great respect, \&c. }
$$


By comparing the indents made in the tin-foil, it appears that the two forces acting in contrary directions are nearly equal; but as no satisfactory conclusion could be drawn from these phænomena, I contrived an electrometer, by which these forces are compared to as great a degree of precision as the nature of the subject seems to require.

In fig. 3. Plate II. $A B C D$ is a card placed in a vertical position upon a stand; EF, two thin pieces of mabogany which slide upon the card, by means of slits cut in them with a fine saw.

$p x$ and $n x$ two pieces of wire sliding through $\mathrm{E}$ and $\mathrm{F}$; $p x$ is placed on one side of the eard and $n x$ on the other, their ends being opposite to one another at the point $x$.

$G$, a piece of wood fixed upon the top of the card, from which two pendulums of equal dimensions and weight are suspended at $b$, on opposite sides of the card, having the centres of their bobs covering the points of the wires at $x$. One of these pendulums $a x$ is suspended on this side of the card, upon the pin $b$; but the other, being on the other side of the card, is not seen in the figure. The pendulum rods are made of very thin slips of mahogany, and the bobs of card paper.

When the instrument is adjusted, the ends of the wires are placed exactly between the two centres of the bobs at $x$, where a small circular opening is made, between the ends of the two pieces of wood, to give free passage to the electric fluid.

When a charge from a coated surface is passed through the wires, the card is perforated, and the pendulums are thrown off in contrary directions; and, as far as I an able to judge by inspection, to equal distances from the perpendicular*.

Hence it appears an established law of nature, that all electrical phenomena are produced, by two distinct powers acting in contrary directions, and with equal energv.

And these invisible agents seem to exist in erery particle of matter, either in a state of rest or a state of action, according to their different modifications. But fill that law which governs these modifications shall be perfectly understood, we must be content with observing effects, without knowing their causes.

To be continued in my next communication.

I am, dear sir, your obedient servant, Lynn, August 4, 1818.

Ez. WALKer.

- As the wires $n x p$ and the point of suspension of the pendulums are adjustable, the came card may serve for many experiments. 